\title{
Random-Texturing of Phosphorus-Doped Layers for Multi-Crystalline Si Solar Cells by Plasmaless Dry Etching
}

\author{
Yoji Saito $^{1,2}$, Akira Kubota ${ }^{2}$, Shigeto Iwama ${ }^{2} \&$ Ryosuke Watanabe $^{1}$ \\ ${ }^{1}$ Department of System Design Engineering, Seikei University, Tokyo, Japan \\ ${ }^{2}$ Department of Electrical and Mechanical Engineering, Seikei University, Tokyo, Japan \\ Correspondence: Yoji Saito, Department of System Design Engineering, Seikei University, 3-3-1 \\ Kichijoji-Kitamachi, Musashino, Tokyo 180-8633, Japan. Tel: 81-422-373-725. Fax: 81-422-37-3871. E-mail: \\ yoji@st.seikei.ac.jp
}

Received: March 25, 2014 Accepted: April 9, 2014 Online Published: June 25, 2014

doi:10.5539/mas.v8n4p8 URL: http://dx.doi.org/10.5539/mas.v8n4p8

\begin{abstract}
We investigated a texturing process for crystalline $\mathrm{Si}$ solar cells by dry etching with chlorine trifluoride $\left(\mathrm{ClF}_{3}\right)$ gas without plasma excitation. Recently our research group demonstrated improved electrical characteristics of single-crystalline $\mathrm{Si}$ solar cells textured by dry etching of the phosphorus-doped layers. In this report, we attempted to improve the electrical properties of multi-crystalline Si solar cells by modifying the experimental procedure and optimizing the process conditions. The reflectance of the treated surfaces was around $10 \%$ at 600 $\mathrm{nm}$ without an anti-reflection film. We demonstrated the characteristics of multi-crystalline solar cells by random-texturing by plasmaless etching. This is the first report to prove the validity of plasmaless dry texturing for multi-crystalline Si solar cells.
\end{abstract}

Keywords: reflectance, diffused layer, spectral response, chlorine trifluoride, multi-crystalline $\mathrm{Si}$

\section{Introduction}

A current goal in research for semiconductor solar cells is to develop a low-cost method for fabricating cells with high conversion efficiency. One of the methods for improving efficiency is to reduce the surface reflection loss of the incident light. Texturing is one of the methods for reducing surface reflection loss, and will be important for light trapping especially in future thin crystalline Si solar cells because of the relatively low absorption coefficient of Si.

(100) oriented single-crystalline Si substrates are mainly textured into pyramid-like structures with an alkaline solution by using the dependence of the etch rate on crystalline direction (Campbell \& Green, 1987). However, an alkaline solution is not effective for texturing multi-crystalline Si. Random-textured structures created by wet etching with mixed acid solutions, $\mathrm{HF} / \mathrm{HNO}_{3} / \mathrm{CH}_{3} \mathrm{COOH}$ (Nishimoto et al., 1999; Hauser et al., 2004; Nievendick et al., 2012) or $\mathrm{HF} / \mathrm{HNO}_{3} / \mathrm{H}_{2} \mathrm{SO}_{4}$ (Watanabe et al., 2013) for multi-crystalline $\mathrm{Si}$ have been investigated, but they are insufficient for obtaining a low reflectance. Moreover, the wet process will be difficult for thin substrates with low mechanical strength in the future.

Reactive-ion etching (RIE) using plasma is known to form textured structures on multi-crystalline Si surfaces at specific etching conditions. Inomata et al. (1997) reported around 17\% efficiency for multi-crystalline Si solar cells textured by RIE with a $\mathrm{Cl}_{2}$ gas, but the detailed experimental condition was not given. Various pieces of research indicated low reflectance below $4 \%$ textured by RIE with $\mathrm{SF}_{6} / \mathrm{O}_{2}$ (Murias et al., 2012) and $\mathrm{NF}_{3} / \mathrm{Ar}$ (Cecchetto et al., 2013) gas mixtures, but the characteristics of the solar cells have not been referred. Recently Park et al. (2013) reported around $16.8 \%$ efficiency for multi-crystalline $\mathrm{Si}$ solar cells with cone and pyramid-like textured structures formed by RIE with $\mathrm{SF}_{6} / \mathrm{O}_{2}$. However, the RIE method often has disadvantages, such as plasma damage to the substrates (Yoo et al., 2008), contamination (Tucci et al., 2006), and high throughput mass production of solar cells. A different, low-cost, and damageless texturing method is considered to be required.

Our research group has intensively investigated a procedure for texturing crystalline Si by dry etching without plasma. The $\mathrm{ClF}_{3}$ gas can etch silicon even at room temperature without plasma (Ibottoson et al., 1984). In addition, plasmaless dry etching is an isotopic reaction, and hardly damages substrates (Saito \& Kosuge, 2007). 
In particular, the dry etching with $\mathrm{ClF}_{3}$ gas can form random-textured structures on $\mathrm{Si}$ (Kohata \& Saito, 2010; Sanda \& Saito, 2013).

We can easily obtain a low reflectance near $10 \%$ at wavelengths between $300-800 \mathrm{~nm}$ for Si surfaces randomly textured by $\mathrm{ClF}_{3}$. We fabricated solar cells by phosphorus thermal diffusion onto the textured surfaces. However, the increase of efficiency of the random-textured solar cells was below $10 \%$. This value was less than the increase of the absorbed light in the cells, around 35\%. The insufficient improvement was considered to be due to submicron structures caused by the dry texturing (Kohata \& Saito, 2010).

Recently, we etched dry-textured surfaces with an acid solution to form appropriately-textured structures. Improved electrical characteristics were obtained for solar cells with dry-textured and wet-etched surfaces (Sanda \& Saito, 2013). However, the two step process will not be preferred because of cost increase in practical fabrication.

In the related previous report (Kohata \& Saito, 2010), we attempted to enhance the performance of dry textured solar cells by modifying the experimental procedure. Phosphorus-doped emitter layers were slightly etched with $\mathrm{a} \mathrm{ClF}_{3}$ gas to texture the cell surfaces. The textured surfaces had a reflectance of about $17.8 \%$ at a wavelength of $600 \mathrm{~nm}$. We fabricated single-crystalline Si solar cells with a textured doped layer, and their efficiency was sufficiently improved in comparison with that of the mirrored cell.

In this study, the emitter etch-back texturing process was applied to the fabrication of multi-crystalline silicon solar cells in order to prove the validity of plasmaless texturing for multi-crystalline substrates. We attempted to improve the electrical performances by modifying the fabrication step and optimizing the experimental conditions.

\section{Experimental Details}

P-type multi-crystalline Si substrates with a resistivity of $0.5-1.5 \Omega \mathrm{cm}$ and a thickness of $250 \mu \mathrm{m}$ were used and were cut to a size of $2 \mathrm{~cm} \times 3 \mathrm{~cm}$. The substrates were etched with a hydrofluoric acid and nitric acid-based solution to remove slice-induced damaged layers and were cleaned with a hot ammonia and hydrogen peroxide-based solution. Schematic diagrams for the following fabrication process flow of solar cells are summarized and shown in Figs. 1(a)-(i). After the chemical cleaning, a pn junction was formed by thermal diffusion of phosphorus as shown in Fig. 1(a). The aluminum films were prepared by evaporation as shown in Fig. 1(b), and the films were patterned to the front side electrodes as shown in Fig. 1(c). The detailed process conditions up to this step are described elsewhere (Kohata \& Saito, 2010).

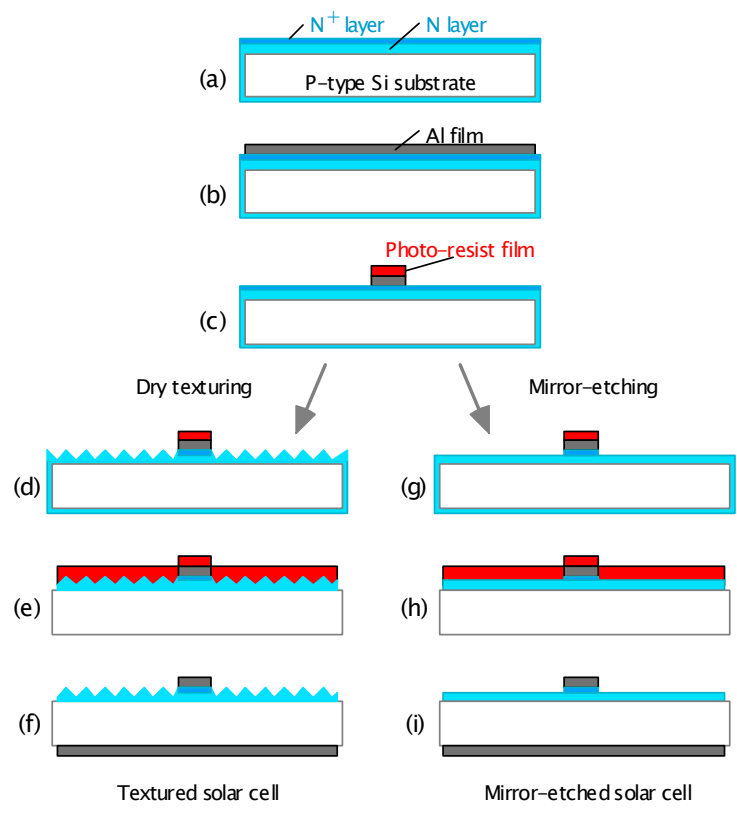

Figure 1. Schematic diagrams of procedure fabricating textured and mirror-etched cells

Note. (a) Phosphorus diffusion, (b) Al evaporation, (c) Al patterning, (d) Texturing of diffused layer, (e) Photo-resist patterning, (g) Isolation and Al evaporation onto rear side, (h) Mirror-etching of diffused layer, (i) Isolation and $\mathrm{Al}$ evaporation onto rear side. 
We introduced the substrates into the dry etching apparatus, described elsewhere (Saito \& Kosuge, 2007). The substrates were, then, partially textured by $\mathrm{ClF}_{3}$ at room temperature by using the patterned photo-resist and aluminum electrodes as an etching mask as shown in Fig. 1(d), where the typical partial pressure of $\mathrm{ClF}_{3} \mathrm{was}_{1.2}$ $\mathrm{Pa}$. The photo-resist film was intentionally left to reduce fluorination of metal films during etching.

In the conventional process for cell fabrication, the substrate surfaces are usually textured before the phosphorus diffusion step. The dry texturing can be performed even after electrode formation, because dry etching has a high selectivity of etch rates respective to mask materials. Moreover, we are able to form a selective emitter structure self-alignedly during the texturing step.

The extra phosphorus-doped layers of the substrates were etched with an acid solution for 1 min as shown in Fig. 1(e). The area of the left doped layer was measured to be $4.32 \mathrm{~cm}^{2}$. In our previous study (Kohata \& Saito, 2010), the extra diffused layers were removed before aluminum evaporation, and the cell yield was low due to pin holes in the diffused layers because of the insufficient resistance of the photo resist films to an acid solution. The cell yield was remarkably increased by the modification in this study.

The aluminum was evaporated to the rear surface, as shown in Figure 1(f), and the substrates were finally annealed at $500^{\circ} \mathrm{C}$ in nitrogen ambient to form ohmic contacts.

Solar cells with mirror-etched surfaces were also prepared as reference samples. The experimental procedure for the mirror-etched cell was similar to the above mentioned procedure until Figure 1(c). After the front electrode patterning, a part of the $n+$ layer was etched back with an acid solution to adjust the thickness and sheet resistance of the doped layer to those of the textured cells, as shown in Figure 1(g).

Optical reflection of the substrates was measured in a wavelength range between $300-850 \mathrm{~nm}$ with a spectrophotometer by using an integrating sphere. Surface structures were characterized by using a scanning electron microscope (SEM). The current-voltage characteristics of the cells were measured at $25^{\circ} \mathrm{C}$ under an illumination of AM1.5 from a solar-simulated light source. The spectra response of the cells was also measured.

\section{Results and Discussion}

\subsection{Surface Structures, Optical Properties, and Sheet Resistance}

As received multi-crystalline $\mathrm{Si}$ substrates were mirror-etched with an acid solution ( $\mathrm{HF}: \mathrm{HNO}_{3}: \mathrm{CH}_{3} \mathrm{COOH}=$ 2:3:6) for 1 min. A typical SEM image of the mirror-etched surfaces is shown in Figure 2. The morphology of the etched surface is rather smooth in the microscopic region, but is gently rough at a scale of a few micrometers. The gentle roughness is likely derived from the as-cut surface structures of the substrates. The starting surface structures are different from those of single-crystalline Si substrates, because multi-crystalline Si wafers are not polished.

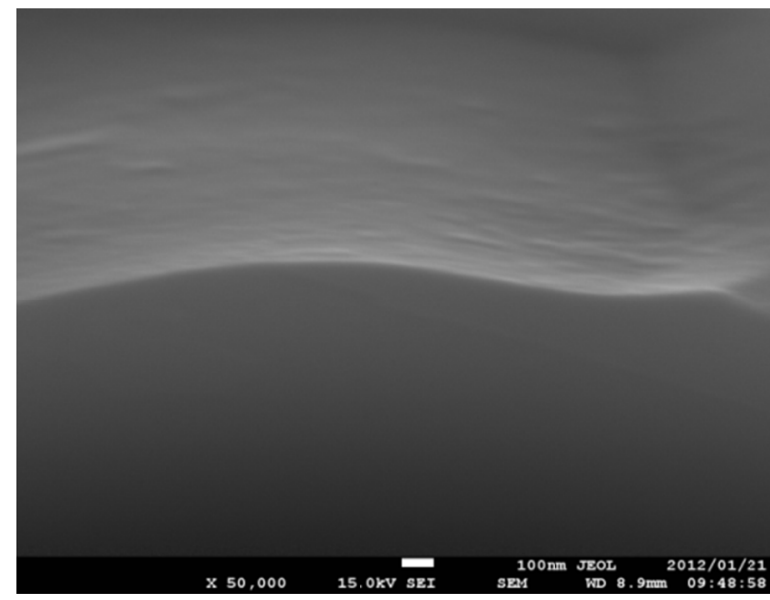

Figure 2. Typical SEM image of phosphorus-doped multi-crystalline Si substrate mirror-etched with an acid solution

Phosphorus was thermally diffused onto the substrate surfaces and the surfaces were textured by $\mathrm{ClF}_{3}$ with a partial pressure of 1.2 $\mathrm{Pa}$ at room temperature. SEM images of the surfaces, dry-textured for 3, 6, and 9min, are shown in Figs. 3 (a), (b), and (c), respectively. Every SEM image in Figure 3 shows microscopic roughness and is similar to each other. The roughness is induced in the early stage of the dry etching and gradually changes in 
the following stage.

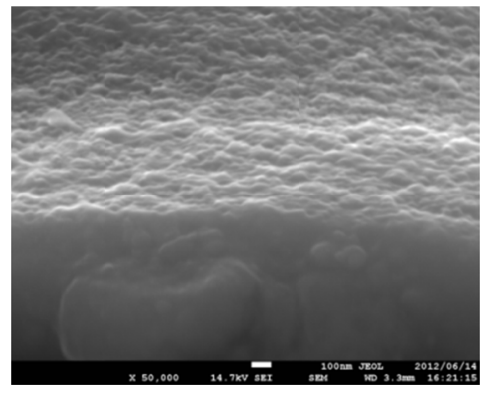

(a)

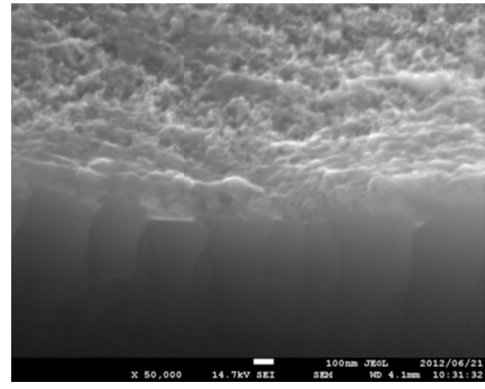

(b)

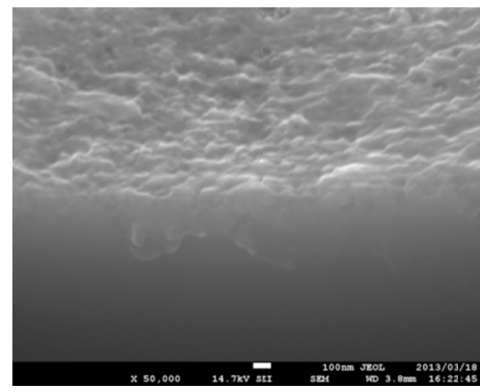

(c)

Figure 3. SEM images of phosphorus-doped multi-crystalline Si substrates etched at $\mathrm{ClF}_{3}$ partial pressure of 1.2 Pa for (a) 3, (b) 6, and (c) 9 min

Figure 4 shows reflectance spectra for the textured and mirror-etched surfaces. As the texturing time increases, the reflectance of the textured surfaces decreases, as shown in Figure 4. A low reflectance below $10 \%$ at $600 \mathrm{~nm}$ is achieved for the substrates etched for $4 \mathrm{~min}$ and longer and is less than that for the textured single-crystalline substrates reported in the previous related article (Kohata \& Saito, 2010).

In Figure 4, the decrease of the reflection of the textured surfaces respective to that of the mirror-etched surfaces is remarkable with the decrease of the wavelength. This tendency is due to the increase of the effect of multiple reflections, because light with short wavelengths can enter into sub-micron holes in the textured structures. For example, the light reflects more than three times at a wavelength of $400 \mathrm{~nm}$, as estimated from the reflectance value. By the way, the reflectance of textured surfaces gradually increases with the increase of the wavelength over $500 \mathrm{~nm}$, because multiple reflections are prevented. The textured "layers" work as anti-reflection films with graded refractive indices (Sai et al., 2007).

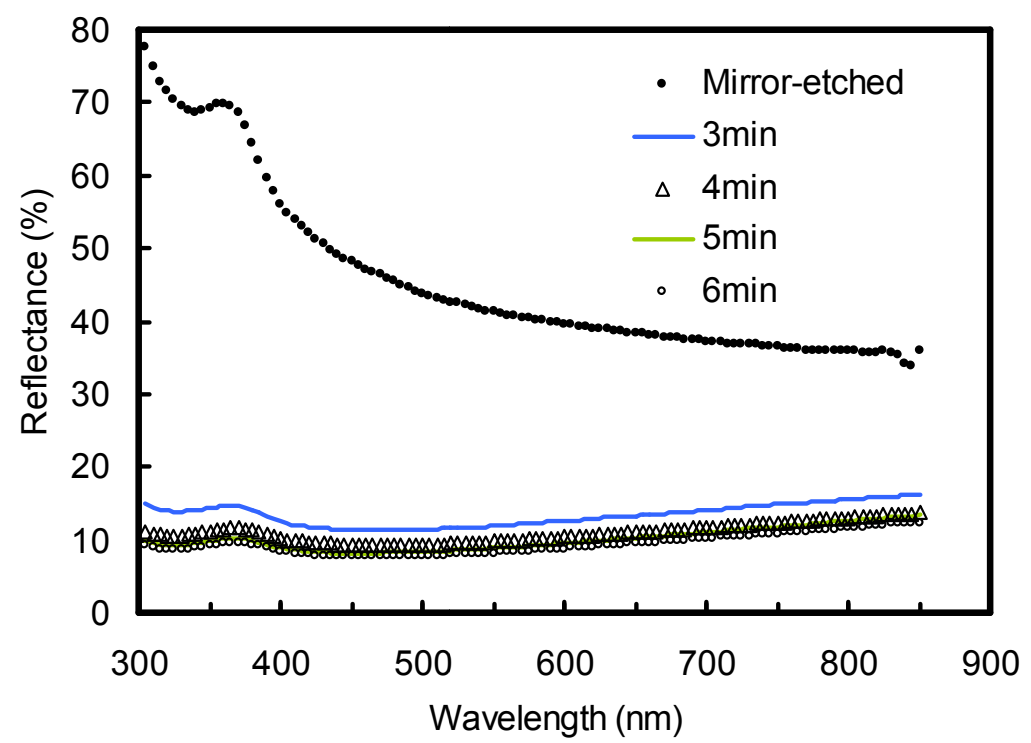

Figure 4. Reflectance spectra of multi-crystalline $\mathrm{Si}\left(\mathrm{ClF}_{3}\right.$ partial pressure : 1.2 $\left.\mathrm{Pa}\right)$

Figure 5 shows reflectance at $600 \mathrm{~nm}$ and the sheet resistance of phosphorus diffused mc-Si as a function of dry etching time, where the $\mathrm{ClF}_{3}$ partial pressure was $1.2 \mathrm{~Pa}$. The reflectance at $600 \mathrm{~nm}$ is replotted from Figure 4, and decreases with the etching time, because the surface roughness increases. The sheet resistance increases, because the thickness of the diffused layers is decreased. In our experiments, sheet resistance of about $50 \Omega /$ sq. is suitable for obtaining high conversion efficiency. Therefore, an etching time range between 4 and 6 min was estimated to be preferable for keeping a low reflectance and suitable sheet resistance. It is not so difficult to control the sheet resistance because of the enhanced etch rate of the $n+$ layer and relatively-suppressed reaction with the other region in the plasmaless dry etching of silicon. 


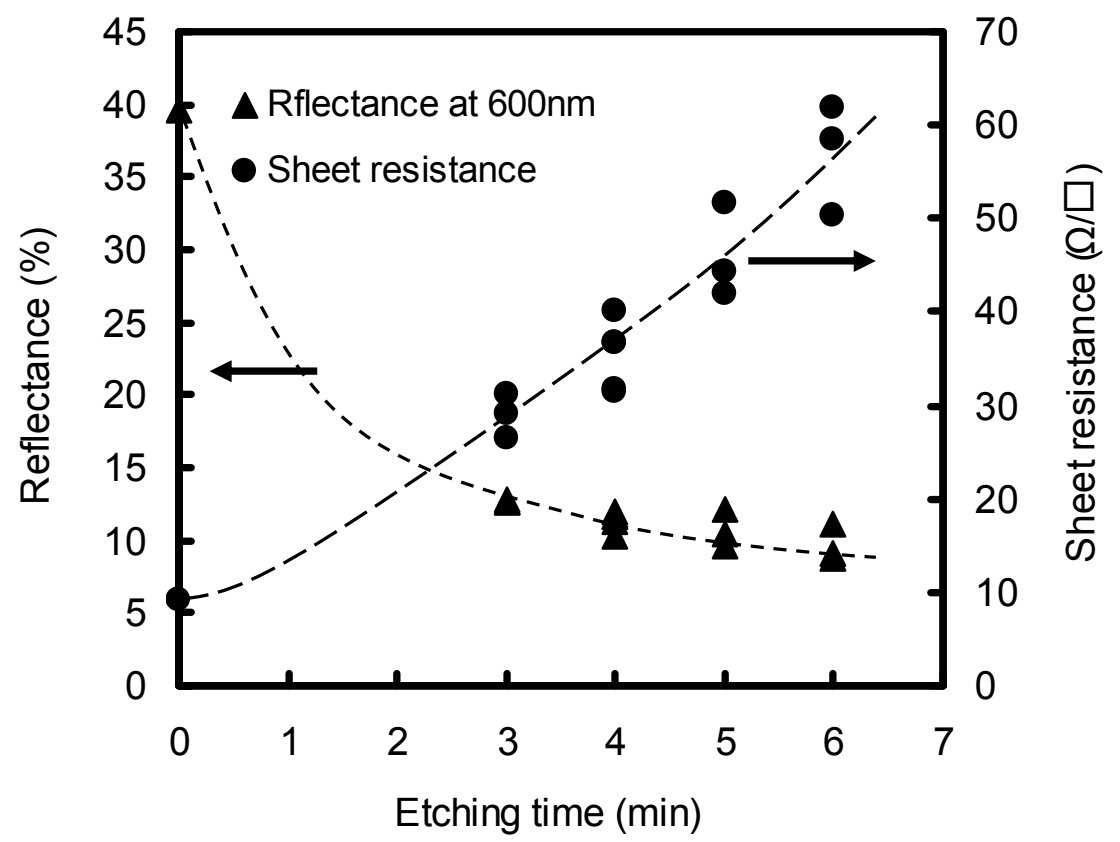

Figure 5. Reflectance at $600 \mathrm{~nm}$ and sheet resistance of phosphorus-doped multi-crystalline Si as function of dry etching time $\left(\mathrm{ClF}_{3}\right.$ partial pressure: $\left.1.2 \mathrm{~Pa}\right)$

\subsection{Characteristics of Dry-Textured Cells}

Dry textured and mirror-etched multi-crystalline Si solar cells were fabricated. The sheet resistance of the mirror-etched surface was near $50 \Omega / \mathrm{sq}$. in this experiment. As shown in Figure 5, the thickness of the n-type layer for the mirrored cell corresponds to that of the cell dry-textured for $5-6 \mathrm{~min}$.

Electrical characteristics for the solar cells illumination were measured under AM1.5 at $25^{\circ} \mathrm{C}$. The current density was obtained by dividing the current by the aperture area, $3.42 \mathrm{~cm}^{2}$, of the solar cell.

Table 1. Dependence of cell performance parameters on texturing time

\begin{tabular}{lllll}
\hline & $\mathrm{V}_{\mathrm{oc}}(\mathrm{mV})$ & $\mathrm{J}_{\mathrm{sc}}\left(\mathrm{mA} / \mathrm{cm}^{2}\right)$ & $\mathrm{FF}$ & $\eta(\%)$ \\
\hline Mirror-etched & 552 & 27.9 & 0.717 & 11.0 \\
Textured (3min) & 559 & 34.6 & 0.746 & 14.4 \\
Textured (4min) & 554 & 34.9 & 0.724 & 14.0 \\
Textured (5min) & 564 & 35.5 & 0.747 & 15.0 \\
Textured (6min) & 561 & 37.8 & 0.717 & 15.2 \\
Textured (7min) & 570 & 30.5 & 0.743 & 12.9 \\
Textured (8min) & 578 & 30.5 & 0.718 & 12.7 \\
Textured (9min) & 446 & 27.0 & 0.318 & 3.9 \\
\hline
\end{tabular}

The cell performance parameters, obtained from the measured current vs. voltage characteristics, are summarized in Table 1. The short circuit current density, Jsc, and the conversion efficiency, $\eta$, of the textured cell were improved up to about $35 \%$ and $38 \%$ compared with those of a mirror-etched cell, respectively. The cell performance was improved with the texturing time until $6 \mathrm{~min}$, because the reflectance decreased and the sheet resistance approached an empirically appropriate value of about 50 /sq., as shown in Figure 5. In this study, the best performance was obtained for the cell textured for $6 \mathrm{~min}$. The cell performance, especially Jsc, was degraded with the texturing time over $7 \mathrm{~min}$, probably because the remaining n-layer became partially too thin.

The absolute spectral responses of the textured cell $(6 \mathrm{~min})$ and the mirrored cell, which were obtained from the 
ratio of the photo-induced current with respect to the light intensity at each wavelength, are shown in Figure 6. The absolute spectral response of the textured cell is larger than that of the mirrored cell at wavelengths over 470 $\mathrm{nm}$. The improved spectral response is mainly due to the increase of the absorbed light by the textured structure.

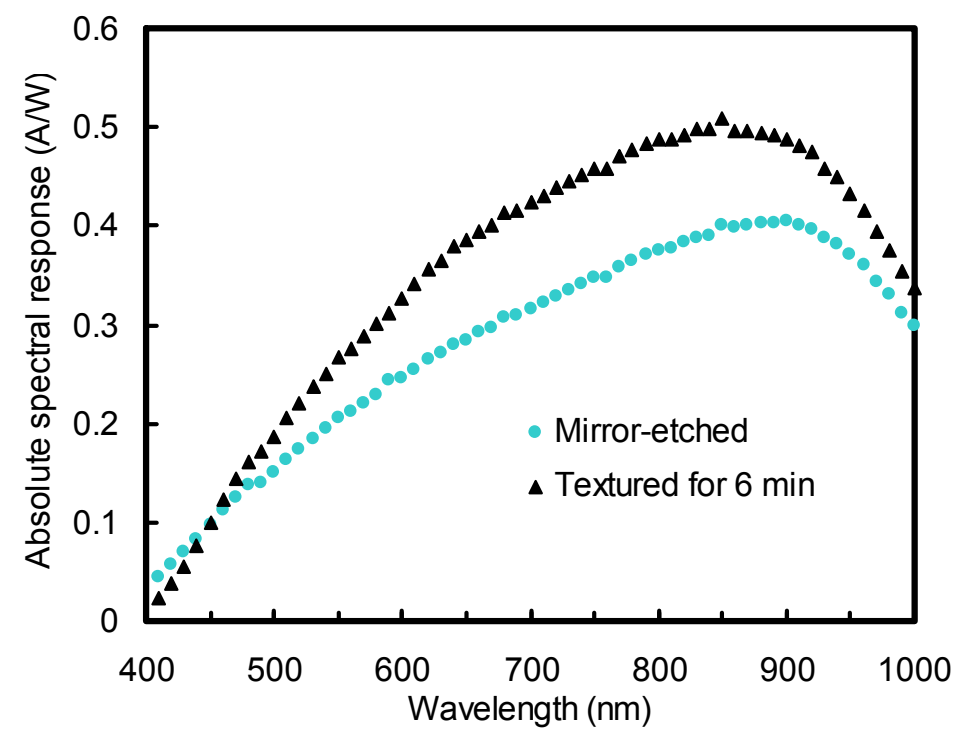

Figure 6. Absolute spectral responses of textured cell (6 min) and mirrored cell, which were obtained from ratio of photo-induced current with respect to light intensity

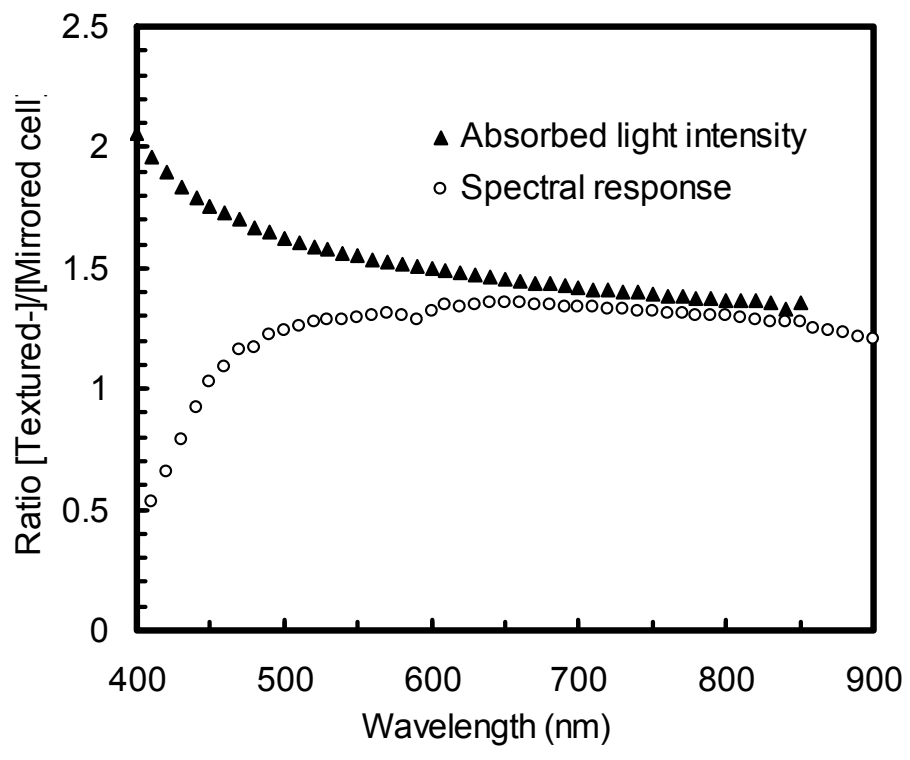

Figure 7. Ratios of spectral response and absorbed light intensity of textured cell with respect to those of mirrored cell

Figure 7 shows the ratios of the spectral response and the absorbed light intensity of the textured cell with respect to those of the mirrored cell, where the absorbed light intensity is calculated from the reflectance shown in Figure 4. The values of the ratio of the spectral response almost agree with those of the absorbed light intensity at each wavelength over $650 \mathrm{~nm}$. The improvement of the spectral response, therefore, corresponds to the increase of absorbed light in the long wavelength region.

However, the values for the spectral response largely deviate from those for the absorbed light intensity in the short wavelength region below $500 \mathrm{~nm}$ as shown in Figure 7. The degradation of the spectral response is considered to be due to the decrease of internal quantum efficiency (IQE). 
Cross-sectional diagrams near the phosphorus-diffused layers textured by the dry process are illustrated in Figure 8 to explain the degradation of IQE in the short wavelength region. Most of the incident light with wavelengths larger than $500 \mathrm{~nm}$ enters into the region near the pn junction interface, and the photo-induced minority carriers (holes) can contribute to the current as shown in Figure 8(a). On the other hand, most of the incident light with wavelengths around $400 \mathrm{~nm}$ is estimated to be absorbed within an $80 \mathrm{~nm}$ depth from the surfaces because of large absorption coefficients, as shown in Figure 8(b). A large part of the photo-induced minority carriers near the surfaces will recombine and diminish likely due to surface states, the residual $\mathrm{n}+$ region, and/or the long pathway to the junction interface. In the short wavelength region, the IQE of the textured cell is less than that of the mirrored cell, in which the $\mathrm{n}+$ region is removed by the wet etching. Moreover, the reflectance of the textured surfaces is much less than that of the mirrored surface because of multi-reflection in the short wavelength region. These cause the deviation between the improvement of spectral response and the increase of absorbed light intensity by the texturing, as indicated in Figure 7 .

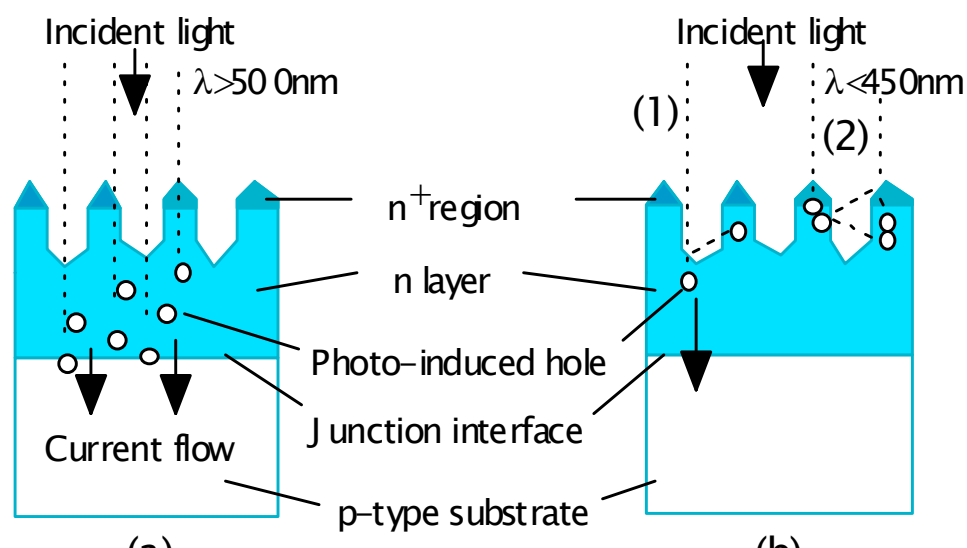

(a)

(b)

Figure 8. Schematic cross-sectional images for models of light absorption and photo-induced carriers in a phosphorus-diffused surface of $\mathrm{Si}$ with finely-textured structures

Note. Wavelengths of incident light are (a) below $450 \mathrm{~nm}$ and (b) over $500 \mathrm{~nm}$.

If the IQE is improved to that of the wet-etched cell, the increase of the short circuit current is estimated to be a few percent. A method for improving the low IQE in the short wavelength region is under investigation. We consider that surface passivation can improve the IQE.

\section{Conclusion}

In this study, we applied plasmaless dry texturing to doped layers of multi-crystalline Si solar cells. We modified the fabrication procedure and optimized the etching conditions to improve the cell performance. The reflection of the textured surface was decreased to about $10 \%$ at $600 \mathrm{~nm}$. The efficiency of the fabricated cell with the textured surfaces was improved up to $38 \%$, compared with that of the mirror-etched cell. It was experimentally demonstrated that our texturing method is effective for multi-crystalline Si solar cells. The next goal for this texturing procedure is to improve IQE in the short wavelength region to improve cell performance further.

\section{Acknowledgments}

The authors are grateful to Mr. Momma and Mr. Miyasaka for the technical assistance. They also thank Central Glass Co. Ltd. and Sharp Co. for supplying the $\mathrm{ClF}_{3}$ gas and multi-crystalline Si substrates.

\section{References}

Campbell, P., \& Green, M. A. (1987). Light trapping properties of pyramidally textured surfaces. Journal of Applied Physics, 62, 243-249. http://dx.doi.org/10.1063/1.339189

Cecchetto, L., Serenelli, L., Agarwal, G., Izzi, M., Salza, E., \& Tucci M. (2013). Highly textured multicrystalline silicon surface obtained by dry etching multi-step process. Solar Energy Materials \& Solar Cells, 116, 283-290. http://dx.doi.org/10.1016/j.solmat.2013.04.015

Hauser, A., Melnyk, I., Wefringhaus, E., Delahaye, F., Vilsmeier, G., \& Fath, P., (2004). Acidic texturisation of multi-crystalline Si using high throughput in-line prototype system with no organic chemistry: Proceedings of 19th European Photovoltaic Solar Energy Conference, 2004 (pp. 1094-1097) 
Ibottoson, D. E., Mucha, J. A., Flamm, D. L., \& Cook J. M. (1984). Plasmaless dry etching of silicon with fluorine containing compounds. Journal of Applied Physics, 56, 2939-2492. http://dx.doi.org/10.1063/1.333834

Inomata, Y., Fukui, K., \& Shirasawa, K. (1997). Surface texturing of large area multicrystalline silicon solar cells using reactive ion etching method. Solar Energy Materials \& Solar Cells, 48, $237-242$. http://dx.doi.org/10.1016/S0927-0248(97)00106-2

Kohata, H., \& Saito, Y. (2010). Maskless texturization of phosphorus-diffused layers for crystalline Si solar cells by plasmaless dry etching with chlorine trifluoride gas. Solar Energy Materials \& Solar Cells, 94, 2124-2128. http://dx.doi.org/10.1016/j.solmat.2010.06.040

Murias, D., Reyes-Betanzo, C., Moreno, M., Torres, A., Itzmoyotl, A., Ambrosio, R., Soriano, M., Lucas, J., \& Cabarrocas R. P. (2012). Black Silicon formation using dry etching for solar cells applications. Materials Science and Engineering, B 177, 1509-1513. http://dx.doi.org/10.1016/j.mseb.2012.03.038

Nievendick, J., Zimmer, M., Souren, F., Haunschild, J., \& Rentsch J., (2012). Relation between solar cell efficiency and crystal defect etching induced acidic texturization on multicrystalline silicon material. Solar Energy Materials \& Solar Cells, 105, 159-166. http://dx.doi.org/10.1016/j.solmat.2012.05.023

Nishimoto, Y., Ishihara, T., \& Namba, K. (1999). Investigation of Acidic texturization for multicrystalline silicon solar cells: Journal of Electrochemical Society, 146, 457-461. http://dx.doi.org/10.1149/1.1391628

Park, K. M., M. B. Lee, J. W. Shin, \& S. Y. Choi, (2013). Investigation of surface features using reactive ion etching method for the enhanced performance of multi-crystalline silicon solar cells. Solar Energy, 91, 37-47. http://dx.doi.org/10.1016/j.solener.2012.12.023

Sai, H., Kanamori, Y., Arafune, K., Ohshita, Y., \& Yamaguchi M. (2007). Light trapping effect of submicron surface textures in crystalline Si solar cells. Progress in Photovoltaic Research and Applications, 15, 415-423. http://dx.doi.org/10.1002/pip.754

Saito, Y., \& Kosuge, T. (2007). Honeycomb-textured structures on crystalline silicon surfaces for solar cells by spontaneous dry etching with chlorine trifluoride gas. Solar Energy Materials \& Solar Cells, 91, 1800-1804. http://dx.doi.org/10.1016/j.solmat.2007.06.009

Sanda, T., \& Saito, Y. (2013). Texturization for multi-crystalline silicon solar cells with chlorine trifluoride gas and acid solution. IEICE Transaction on Electronics, E96-C, $289-291$. http://dx.doi.org/10.1587/transele.E96.C.289

Tucci, M., Serenelli, L., Iuliis, S. De, Salza, E., \& Pirozzi L. (2006). Dry $\mathrm{NF}_{3} / \mathrm{O}_{2}$ plasma texturing of multicrystalline silicon. Proceeding of the 21st European Photovoltaic Solar Energy Conference 2006, (p.1250).

Watanabe, R., Abe, S., Haruyama, S., Suzuki, T., Onuma, M., \& Saito, Y. (2013). Evaluation of a new acid solution for texturization of multi-crystalline silicon solar cells. International Journal of Photoenergy, 2013(2013), 1-6. http://dx.doi.org/10.1155/2013/951303

Yoo, J., Kim, K., Thamilselvan, M., Lakshminarayn, N., Kim, Y. K., Lee, J., .. Yi, J. (2008). RIE texturing optimization for thin c-Si solar cells in SF6/O2 plasma. Journal of Physics, D: Applied Physics, 41(12). http://dx.doi.org/10.1088/0022-3727/41/12/125205

\section{Copyrights}

Copyright for this article is retained by the author(s), with first publication rights granted to the journal.

This is an open-access article distributed under the terms and conditions of the Creative Commons Attribution license (http://creativecommons.org/licenses/by/3.0/). 